\title{
COVID-19 and health literacy: the yell of a silent epidemic amidst the pandemic
}

\author{
(iD) Luana Resende Cangussú \\ (iD) Igor Rafael Pereira de Barros ${ }^{2}$ \\ (iDCarlos Alberto de Lima Botelho Filho' \\ (D) arbas Delmoutiez Ramalho Sampaio Filho' \\ (iD) Matheus Rodrigues Lopes ${ }^{1}$
}

1. Universidade Federal do Vale do São Francisco, campus Paulo Afonso, Paulo Afonso, BA, Brasil. 2. Universidade de Pernambuco, campus Serra Talhada, Serra Talhada, PE, Brasil.

\section{SUMMARY}

The emergence of a new form of Coronavirus (SARS-CoV-2) exposed weaknesses of health services in several countries, with overcrowding of hospitals, and lack of supplies and professionals in combating the disease, which sometimes contributed to the installation of social, political, and economic chaos. The critical situation experienced made the subject widely publicized so that the current pandemic also deals with an information epidemic. However, the data received and transmitted require prior critical analysis of its content, although not everyone is able to make the necessary judgment before using or sharing information, partly due to the lack of adequate health knowledge. Health literacy is a broad and important topic in public health but still globally underestimated, thus considered a silent epidemic. The exponential increase in the number of confirmed cases shows the world population's inadequacy and difficulty in understanding basic prevention guidelines. The COVID-19 pandemic warns of gaps in the health literacy levels of the world population and exposes the need for a comprehensive mapping to identify the overall health literacy status in more countries.

KEYWORDS: Coronavirus Infections. Health Literacy. Pandemics. Betacoronavirus.

The emergence of a new form of Coronavirus (SARS-CoV-2) in China, in December 2019, has been causing major impacts on medicine, science, politics, and society due to the high infectivity of the virus and morbidity and mortality of the disease. In March 2020, the World Health Organization (WHO) officially declared the COVID-19 disease a pandemic, and since then, several countries have adopted isolation and intervention measures, although overcoming the pandemic still represents a major challenge for science. The exposed weaknesses of health services in several countries, with overcrowding of hospitals, lack of supplies, and professionals in combating the disease, sometimes contribute to the installation of social, political, and economic chaos ${ }^{1,2}$.

The catastrophic progression of COVID-19 demanded health agencies to establish rapid intervention measures to curb the spread of the disease ${ }^{2}$. The critical situation experienced made the issue widely disseminated by health organizations, scientific communities, media, and the internet. However, the excess of information does not mean that these

DATE OF SUBMISSION: 21-JUn-2020

DATE OF ACCEPTANCE: $11-J u l-2020$

CORRESPONDING AUTHOR: Matheus Rodrigues Lopes

Universidade Federal do Vale São Francisco (UNIVASF), Campus Paulo Afonso

Rua da Aurora, s/n, quadra 27, lote 3, Alves de Souza, BA, Brasil - 48607-190

E-mail: matheuslopesbio@gmail.com / Tel: +55 75 3282-3456 
sources invariably present content that is reliable and of quality and sometimes false and inaccurate news are broadcast, being quickly absorbed and propagated ${ }^{3}$.

Unlike what happened with the Black Death $\left(14^{\text {th }}\right.$ century) and in the last century with the Spanish Flu, the current pandemic also deals with an information epidemic ${ }^{4}$. Thus, the information received and transmitted requires prior critical analysis of its content, although not everyone makes the necessary judgment before sharing it, partly due to the easiness of spreading news through cell phones, tablets, and computers, and also due to the lack of adequate health literacy ${ }^{5}$.

According to the WHO, health literacy is defined as the patient's ability to obtain, process, and understand health information in order to make judgments and relevant decisions regarding their own health, in their daily lives ${ }^{6}$. In a time like this of the COVID-19 pandemic, full of uncertainties, in which information is constantly changing and a rapid behavior change by the world population is required to reduce the risks of infection and spread of this disease, presenting an adequate level of health literacy has never been more important ${ }^{7}$.

Health literacy is a broad and increasingly important issue in public health. It is well described in the literature that low health literacy causes difficulties in understanding the health-disease process, increases hospitalization rates and costs to health services, hinders medication adherence, impacts the quality of life, and represents a barrier to self-care ${ }^{8,9}$.

However, there are still few studies that identify the level of literacy in different countries. Among some of the places most affected by COVID-19, some studies are highlighted, such as one carried out in Europe through the European Health Literacy Survey (HLS-EU), which identified that about half of the European population presented an insufficient level of health literacy ${ }^{10}$. In Canada, about $60 \%$ of adults have inadequate health literacy, something that is even more pronounced in the elderly population, with approximately $80 \%$ inadequacy ${ }^{11}$. In the United States, through the National Assessment of Adult Literacy (NAAL) survey, it was found that only $12 \%$ of Americans had a proficient level of health literacy $^{12}$. In Brasil, there are no studies of national scope that evaluate health literacy; however, in some regional surveys, it has already been possible to verify a low level of understanding in certain groups of patients ${ }^{13,14}$.
Health literacy is a globally underestimated theme, to the point that many authors consider it a silent epidemic ${ }^{15}$. Historically, the impacts of low health literacy have been observed only in the long term, such as in the negative outcomes of patients with chronic non-communicable diseases that do not adhere to treatment ${ }^{3}$.

With the pandemic of COVID-19, the impacts of low health literacy are being presented in the short term, and in a frightening way. The exponential increase in the number of confirmed cases evidences the world population's inadequacy and difficulty in understanding basic prevention guidelines ${ }^{16}$. The low rate of social isolation is often a reflection of this lack of understanding regarding the most diverse aspects of the disease and of the individual and collective consequences that contamination may cause ${ }^{7}$.

Amidst the growing technological and informational dissemination during the COVID-19 pandemic, an inadequate level of health literacy can expose patients to misunderstanding, especially in communication networks, such as the internet, which exhibit both facts and untruths about the most various subjects ${ }^{17}$. In the face of so much new data, the population suffers from excessive information and consequently has great difficulty in judging the truth of the facts ${ }^{15}$. Thus, it is essential that reliable and relevant guidelines are transmitted in simple language and are easy to access so that they can be widely disseminated and executed. The media must be an ally and not an adversary in this process ${ }^{18}$.

In countries with less socioeconomic development, the situation is even more serious: in Brasil, the spread of SARS-Cov-2 started in the middle and upper classes of society; however, with the advance of the spread of the virus in the lower-income segment, the impacts have been more severe, showing the uneven effects of COVID-19 in this part of the population ${ }^{4}$.

Several factors make these people more vulnerable to contamination, among them the type of employment relationship, the daily need to use public transport, poor access to healthcare, low rate of social isolation, and low health literacy. In these conditions, the presence of the State, through the provision of the minimum conditions of sustenance, is essential to achieve better adherence to social isolation, thus avoiding the spread of the virus and the overload of the health systems ${ }^{19}$.

It is worth noting that the structuring of health services with the increase in the number of intensive 
care unit beds, the acquisition of respirators, and the availability of diagnostic tests cannot solve and contain the problem if there are no joint efforts by health professionals, political agents, researchers, and mainly the population whom, guided by reliable sources and fully understanding the dimension of the problem experienced worldwide, manages to fulfill its social role ${ }^{17}$.

The COVID-19 pandemic warns of the gaps that exist in the health literacy levels of the world population and exposes the need for a comprehensive mapping to identify the general status of health literacy in more countries, especially in those where the profile of health literacy has not yet been traced $^{7}$. In this sense, amplifying the discussions on this extremely relevant and under-recognized theme is essential. The improvement of literacy has been shown to be an effective strategy in health promotion, disease prevention, and control, and in situations such as the one currently experienced, which require rapid actions, representing a unique tool ${ }^{20}$.

\section{Funding}

Data sharing is not applicable to this article because no datasets were generated or analyzed during the current study.

\section{Conflicts of interest}

The authors have no conflicts of interest that are directly relevant to the content of this article.

\section{Author's Contribution}

Luana Resende Cangussú: project idea, design, and writing, final approval of the version to be published; Igor Rafael Pereira de Barros: project design and writing, final approval of the version to be published; Carlos Alberto de Lima Botelho Filho: relevant critical review of the intellectual content, final approval of the version to be published; Jarbas Delmoutiez Ramalho Sampaio Filho: relevant critical review of the intellectual content, final approval of the version to be published; Matheus Rodrigues Lopes: project design, writing, and supervision, relevant critical review of the intellectual content, final approval of the version to be published.

\section{REFERENCES}

1. Lai CC, Shih TP, Ko WC, Tang HI, Hsueh PR. Severe acute respiratory syndrome coronavirus 2 (SARS-CoV-2) and coronavirus disease-2019 (COVID-19): the epidemic and the challenges. Int I Antimicrob Agents. 2020;55(3):105924.

2. Sohrabi C, Alsafi Z, O'Neill N, Khan M, Kerwan A, Al-Jabir A, et al. World Health Organization declares global emergency: a review of the 2019 novel coronavirus (COVID-19). Int J Surg. 2020;76:71-6.

3. Paakkari L, Okan O. COVID-19: health literacy is an underestimated problem. Lancet Public Health. 2020;5(5):e249-50.

4. Ahmed F, Ahmed N, Pissarides C, Stiglitz J. Why inequality could spread COVID-19. Lancet Public Health. 2020;5(5):e240.

5. Zarocostas J. How to fight an infodemic. Lancet. 2020;395(10225):676.

6. World Health Organization. Health literacy: the solid facts. Geneva: World Health Organization; 2013). 73p. [cited 2020 May 13]. Available from: https:// apps.who.int/iris/handle/10665/326432

7. Sentell T, Vamos S, Okan O. Interdisciplinary perspectives on health literacy research around the world: more important than ever in a time of COVID-19. Int J Environ Res Public Health. 2020;17(9):3010.

8. Parnell TA, Stichler JF, Barton AJ, Loan LA, Boyle DK, Allen PE. A concept analysis of health literacy. Nurs Forum. 2019;54(3):315-27.

9. Bostock S, Steptoe A. Association between low functional health literacy and mortality in older adults: longitudinal cohort study. BMJ. 2012;344:e1602.

10. Sorensen K, Pelikan IM, Röthlin F, Ganahl K, Slonska Z, Doyle G, et al; HLS-EU Consortium. Health literacy in Europe: comparative results of the European health literacy survey (HLS-EU). Eur J Public Health. 2015;25(6):1053-8.
11. LeBrun M, DiMuzio |, Beauchamp B, Reid S, Hogan V. Evaluating the health literacy burden of Canada's public advisories: a comparative effectiveness study on clarity and readability. Drug Saf. 2013;36(12):1179-87.

12. Cutilli CC, Bennett IM. Understanding the health literacy of America: results of the National Assessment of Adult Literacy. Orthop Nurs. 2009;28(1):2732; quiz 33-4.

13. Chehuen Neto |A, Costa LA, Estevanin GM, Bignoto TC, Vieira CIR, Pinto $F A R$, et al. Functional health literacy in chronic cardiovascular patients. Cien Saude Colet. 2019;24(3):1121-32.

14. Sampaio HA, Carioca AA, Sabry MO, Santos PM, Coelho MA, Passamai MP. Health literacy in type 2 diabetics: associated factors and glycemic control. Cien Saude Colet. 2015;20(3):865-74.

15. Parker R, Ratzan SC. Health literacy: a second decade of distinction for Americans. J Health Commun. 2010;15(Suppl 2):20-33.

16. Lazcano-Ponce $E$, Alpuche-Aranda $C$. Public health literacy in the face of the COVID-19 pandemic emergency. Salud Publica Mex. 2020;62(3):331-40.

17. Pan A, Liu L, Wang C, Guo H, Hao X, Wang Q, et al. Association of public health interventions with the epidemiology of the COVID-19 outbreak in Wuhan, China. JAMA. 2020;323(19):1-9.

18. Lima DL, Lopes MAAAM, Brito AM. Social media: friend or foe in the COVID-19 pandemic? Clinics (Sao Paulo). 2020;75:e1953.

19. Bezerra ACV, Silva CEMD, Soares FRG, Silva JAMD. Factors associated with people's behavior in social isolation during the COVID-19 pandemic. Cien Saude Colet 2020;25(suppl 1):2411-21.

20. Nguyen HC, Nguyen MH, Do BN, Tran CQ, Nguyen TTP, Pham KM, et al. People with suspected COVID-19 symptoms were more likely depressed and had lower health-related quality of life: the potential benefit of health literacy. J Clin Med. 2020;9(4):965. 